\title{
First record of Corynespora leaf fall disease of Hevea rubber tree in China
}

\author{
Pu Jinji ${ }^{\mathrm{A}}$, Zhang Xin ${ }^{\mathrm{A}}$, Qi Yangxian ${ }^{\mathrm{A}}$, Xie Yixian ${ }^{\mathrm{A}, \mathrm{B}}$, Zhang Huiqiang $^{\mathrm{A}}$ and Zhang He Zh $^{\mathrm{A}}$ \\ A Hainan Key Laboratory of Monitoring and Management of Pests of Tropical Agriculture, Environment and Plant \\ Protection Institute, Chinese Academy of Tropical Agricultural Sciences, Danzhou, Hainan 571737, P.R. China. \\ ${ }^{B}$ Corresponding author. Email: yixian81@126.com
}

\begin{abstract}
Corynespora cassiicola has been found for the first time in China on Hevea rubber tree (Hevea brasiliensis) in south China during a survey in 2006. Symptoms on leaves included fishbone necrosis and spots. Sequence data from the ribosomal ITS operon placed the isolates within the Corynespora cassiicola complex.
\end{abstract}

Hevea rubber (Hevea brasiliensis) is an economically and socially important estate crop commodity in many Asian countries such as Indonesia, Malaysia, Thailand, India, Sri Lanka, China and several countries in Africa. The plantations for rubber trees in China have reached 660800 ha since 2003, with a dry rubber output of $\sim 560000$ tons annually, which makes China rank fifth place in rubber output among natural rubber producing countries in the world (Huijian 2005). The three main rubber cultivation areas in China are Yunnan, Hainan and Guangdong, South China.

Corynespora leaf fall, caused by the fungus Corynespora cassiicola, is one of the most important diseases of Hevea rubber tree in Asia and African countries (Ismail and Jeyanayagi 2003). The disease was reported for the first time in Malaysia (Newsam 1960) and afterwards in India (Ramakirishnan and Pillai 1961). The pathogen affects both young and old leaves and causes leaves to fall all year round. This may lead to a delay in maturation of young rubber trees, yield reduction of mature rubber trees and even plant death on susceptible clones. As this disease causes such damage to the natural rubber industry, the International Rubber Research and Development Board (IRRDB) has repeatedly warned producers of this disease and of the risk of outbreaks (IRRDB 2000). Previous surveys carried out in the main natural rubber producing area of China in 2000 and 2003 failed to detect the disease.

During surveys in Hainan and Yunnan in June, October and November of 2006, diseased leaves of Hevea rubber were collected from two rubber nurseries, located separately in Hekou (Yunnan Province) and Danzhou (Hainan Province), and a young rubber plantation in Danzhou. The disease occurred at low frequency at these three locations. This report provides evidence that the causal organism is $C$. cassiicola. This is the first report of C. cassiicola on Hevea rubber in China.

The disease causes circular or irregular amphigenous spots. Each spot has a brown or white papery centre surrounded by a dark reddish brown ring. A yellow halo surrounds the ring. Usually, the main vein or small veinlets adjacent to the spots become dark coloured giving rise to 'fishbone' or 'railway-track' appearances (Fig. 1 $A, B$ ). Sometimes, the shot hole effect is also noticed on leaves due to the disintegration of the centre of the spots. Severe defoliation of the infected plants was not observed during the survey.

C. cassiicola was always isolated from symptomatic leaves on potato dextrose agar (PDA) or malt extract agar (MEA). Single-spore cultures were established both on PDA and MEA. Isolates were incubated with a $12 / 12 \mathrm{~h}$ light/dark cycle or $12 / 12 \mathrm{~h}$ ultraviolet light/dark cycle using cool white fluorescent or ultraviolet light $\sim 30 \mathrm{~cm}$ above the cultures, at a temperature of $28 \pm 2^{\circ} \mathrm{C}$ for 7 days. The cultures sporulated poorly in these two light treatments. The mycelium transferred from PDA to autoclaved toilet paper sporulated very well. Conidia and conidiophores collected from infected rubber leaves and artificial media were microscopically examined. The morphological characteristics of the specimen and of its conidia agreed with the descriptions for $C$. cassiicola by Ellis and Holliday (1971) (Fig. $1 C-E$ ), although conidia produced on PDA were a little longer: 72.3-765.3 $\times 4.8-21.6 \mu \mathrm{m}$ (mean of 50 conidia $=260.3 \times 9.8 \mu \mathrm{m}$ ) with $2-20$ cells separated by hyaline pseudoseptae.

DNA was extracted from the isolates according to the method described by Stewart and Via (1993) and purified using a DNA extraction kit (Code No.DP208/209, Tiangen Biotech, Beijing) according to the manufacturer's instructions. The entire ITS1-5.8S-ITS2 region of the rDNA of the isolates was amplified by PCR using the primers ITS1 and ITS4 (White et al. 1990) and sequenced. It was identical to two ITS sequences of C. cassiicola (AY238606, AY238605) (Kwon et al. unpubl. data) in GenBank (http://www.ncbi.nlm.nih.gov/blast/). This sequence has been deposited in GenBank (EF198115). The isolate (CFCC 82971) has been deposited into the China Forestry Culture Collection Center, Beijing.

Cultures of three isolates of $C$. cassiicola were grown on PDA in darkness for 7 days. Mycelia were collected by scraping the surface of a culture with a sterile scalpel and then incubated on autoclaved toilet paper in Petri dishes to facilitate sporulation. Conidial suspensions were obtained by shaking the mycelia 

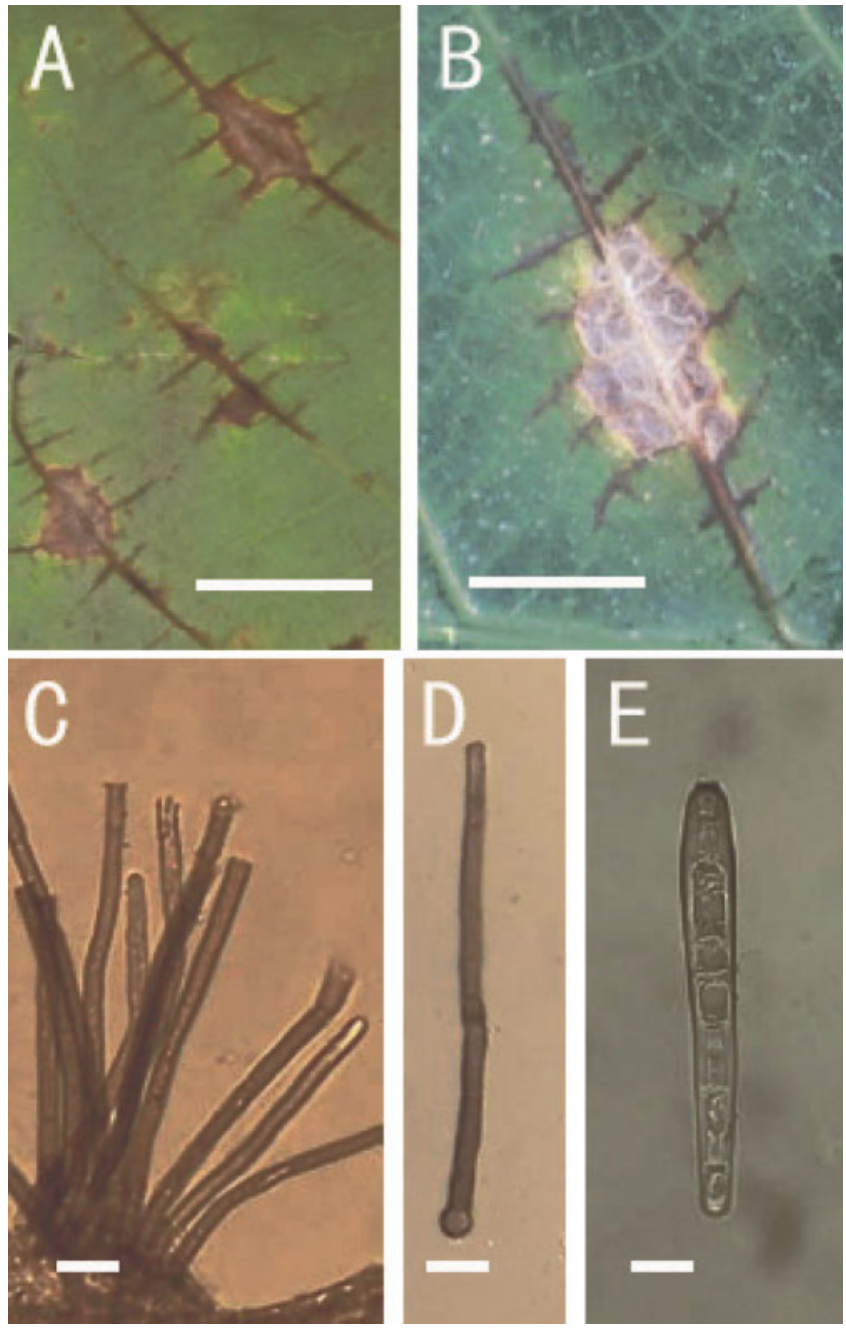

Fig. 1. Corynespora cassiicola CFCC 82971. (A, B) Lesions on leaf of Hevea rubber tree. $(C)$ Fasciculate conidiophores. $(D)$ Conidiophore. (E) Conidium. Bars $A$ and $B=1 \mathrm{~cm} ; C, D$ and $E=10 \mu \mathrm{m}$.

with $100 \mathrm{~mL}$ of sterile distilled water. The conidial suspension was filtered through cheesecloth, estimated and then adjusted to a concentration of $10^{4}$ conidia $/ \mathrm{mL}$. Young, fully expanded healthy leaves of Hevea rubber clone RRIM600 were removed from plants and surfaced sterilised by dipping in $1 \% \mathrm{NaOCl}$ for $10 \mathrm{~s}$ and then washed three times with sterile water. The leaves were then put upside down in individual moist boxes lined with sterile filter paper. Leaves were immediately inoculated with $10 \mu \mathrm{L}$ drops of the conidial suspension. There were seven replicate boxes for each isolate. Controls were inoculated with $10 \mu \mathrm{L}$ of sterile water. Boxes with leaves were placed in the dark for 1 day before transferring to the light for 7 days. Symptoms were recorded 7 days after inoculation. Symptoms similar to those of diseased field plants were observed and C. cassiicola was reisolated from all leaves inoculated with C. cassiicola. All controls treated with distilled water alone had no symptoms and C. cassiicola was recovered from none of the uninoculated controls.

This is the first report of Corynespora leaf fall disease of Hevea rubber tree in China. This disease is considered as one of the most serious diseases of rubber tree in South and South East Asian rubber growing countries. Over the last 20 years most of the high yielding clones grown in this region have been found to be prone to this devastating disease. More work, such as pathogenicity studies of C. cassiicola and resistance of rubber clones, needs to be done in order to determine its potential threat to the Hevea rubber plantation in China.

\section{Acknowledgements}

This work was partly supported by the grants 2004DIA4J012 and 2006NKJ-5 from the Ministry of Agriculture, and Ministry of Science and Technology, the People's Republic of China, respectively. We thank Professor Huang Huasun, Director of Rubber Research Institute of CATAS, for offering Hevea rubber clones used in the pathogenicity trials.

\section{References}

Ellis MB, Holliday P (1971) 'Corynespora cassiicola. CMI description of pathogenic fungi and bacteria, 303.' (Commonwealth Mycological Institute: Kew, UK)

Huijian Z (2005) Production and consumption of Chinese natural rubber. World Tropical Agriculture Information 9, 8-11.

IRRDB (2000) Corynespora leaf fall disease. In 'Annual Report for 2000'. Available at http://www.irrdb.com/IRRDB/AnnualReport/ Report2000.htm\#Corynespora [Verified 16 March 2007]

Ismail H, Jeyanayagi I (2003) Occurrence and identification of physiological races of Corynespora cassiicola of Hevea. In 'Proceedings of IRRDB Symposium 1999’. (Eds QB Chen, JN Zhou) pp. 263-272. (Hainan Publishing House: Haikou)

Newsam A (1960) Plant Pathology Division Report. Rubber Research Institute of Malaysia, Kuala Lumpur, Malaysia.

Ramakirishnan TS, Pillai PNR (1961) Leaf spots of rubber caused by Corynespora Cassiicola. Rubber Board Bulletin 5, 52-53.

Stewart CN, Via LE (1993) A rapid CTAB DNA isolation technique useful for RAPD fingerprinting and other PCR applications. Biological Techniques 14, 748-750.

White TJ, Bruns T, Lee S, Taylor J (1990) Amplification and direct sequencing of fungal ribosomal RNA genes for phylogenetics. In 'PCR protocols: a guide to methods and applications'. (Eds MA Innes, DH Gelfand, JJ Sninsky, TJ White) pp. 315-322. (Academic Press: San Diego)

Manuscript received 18 January 2007, accepted 14 March 2007 